\title{
Hormonal regulation of $\beta$-myosin heavy chain expression in the mouse left ventricle
}

\author{
Mario Patrizio', Marco Musumeci', Ambra Piccone', Carla Raggi ${ }^{2}$, Elisabetta Mattei $^{3}$ \\ and Giuseppe Marano'
}

Departments of ${ }^{1}$ Drug Research and Evaluation and ${ }^{2}$ Cell Biology and Neuroscience, Istituto Superiore di Sanità, Viale Regina Elena 299, 00161 Rome, Italy

${ }^{3}$ Department of Neurobiology and Molecular Medicine, Consiglio Nazionale delle Ricerche, Rome, Italy
Correspondence should be addressed to M Patrizio

Email mario.patrizio@iss.it

\begin{abstract}
We investigated the influence of sex hormones on the expression of $\alpha$ - and $\beta$-cardiac myosin heavy chain isoforms ( $\alpha-\mathrm{MHC}$ and $\beta-\mathrm{MHC}$ ) in $\mathrm{C} 57 \mathrm{bl} / 6$ mice of both sexes under physiological and pathological conditions. In the left ventricles (LVs) of fertile female mice, $\beta-\mathrm{MHC}$ expression was tenfold higher compared with the age-matched males, whereas no difference was found in $\alpha$-MHC expression. These differences disappeared after ovariectomy or in immature mice. We also found a sex-related difference in expression of $\beta$-adrenoceptors $(\beta 1-A R)$, as mRNA levels of this gene were $40 \%$ lower in fertile females compared with males of the same age but did not differ in prepubertal or ovariectomized animals. Interestingly, the deletion of both $\beta 1$ - and $\beta 2$-ARs abolished sex difference of $\beta-\mathrm{MHC}$ expression, as mRNA levels in the LVs of knockout males were increased and reached values comparable to those of knockout females. Moreover, the $\beta 1$-AR antagonist metoprolol induced about a threefold increase in $\beta-\mathrm{MHC}$ expression in adult male mice. The capability of gender to regulate $\beta-\mathrm{MHC}$ expression was also evaluated in the presence of hemodynamic overload. Thoracic aortic coarctation (TAC) produced cardiac hypertrophy along with a 12-fold increase in $\beta-\mathrm{MHC}$ and a $50 \%$ decrease in $\beta 1-A R$ expression in males but not in females, thus abolishing the gender difference observed in sham animals for such genes. By contrast, TAC did not change $\beta 2-A R$ expression. In conclusion, our results show that the expression of $\beta-M H C$ and $\beta 1-A R$ in the LVs undergo gender-related and correlated changes under both physiological and pathological conditions and suggest a role of $\beta 1-A R-m e d i a t e d$ signaling.
\end{abstract}
Key Words
- gender
- gene expression
- $\beta$-myosin
- $\beta$ adrenergic receptors
- cardiac hypertrophy

Journal of Endocrinology (2013) 216, 287-296

\section{Introduction}

Pathological cardiac hypertrophy, which occurs in response to hemodynamic overload, myocardial damage, or defects in sarcomeric proteins, is associated with an enhanced risk of ventricular dysfunction and heart failure. Increased cardiomyocyte size accompanied with the reactivation of so-called fetal genes, such as atrial natriuretic peptide (ANP), skeletal $\alpha$-actin, and $\beta$-myosin heavy chain $(\beta-\mathrm{MHC})$, normally extinguished in adult ventricular myocardium (Izumo et al. 1987, 1988), represents the major hallmarks of pathological cardiac hypertrophy. Gender has been shown to influence the quantitative and qualitative characteristics of pressure overload myocardial remodeling. Premenopausal hypertensive women have a lower prevalence of left ventricular hypertrophy (LVH) than their male counterparts (de Simone et al. 1995, Agabiti-Rosei \& Muiesan 2002), with

Published by Bioscientifica Ltd. 
left ventricular ejection fraction and wall thickness preserved (Cleland et al. 2003, Hogg et al. 2004, Regitz-Zagrosek et al. 2007). This improved ability of females to adapt to hemodynamic overload is also supported and confirmed by several animal studies (Pfeffer et al. 1982, Douglas et al. 1998, Weinberg et al. 1999, Skavdahl et al. 2005). Although gender influence on left ventricular remodeling has been studied extensively, very little is known about the role played by sex hormones on fetal gene expression. Furthermore, the few studies performed in human samples relate to elderly patients (Reiser et al. 2001, Villar et al. 2009). Currently, the reexpression of the fetal gene program is believed to be part of a complex process of adaptation and compensation, aimed to limit cardiac energy consumption and to support cardiac output under an increased hemodynamic load. Thus, a better understanding of molecular mechanisms regulating fetal gene expression could provide important clues for the development of new therapeutic strategies to prevent the transition from hypertrophy to heart failure. Recently, we observed that mRNA levels of $\beta$-MHC were significantly higher $(\approx 10$-fold $)$ in the hearts of female C57bl/6 mice than in those of age-matched male mice of the same strain (Patrizio et al. 2008). To date, however, the mechanism responsible for these differences remains to be determined. To this purpose, we evaluated the influence of ovarian hormones on $\alpha$-MHC and $\beta$-MHC expression in the left ventricle (LV) from C57bl/6 mice of both sexes and different ages, under both physiological and pathological conditions, and from gonadectomized mice. Moreover, we investigated the role of $\beta$-adrenergic receptors ( $\beta$-ARs), the activation of which negatively regulates fetal gene expression (Patrizio et al. 2007, 2008). We found that the LVs from fertile female mice show a greater expression of $\beta$-MHC when compared with age-matched male mice under physiological conditions, and that this difference depends on the presence of ovarian hormones and is related to a lower expression of the $\beta 1$-AR. For the first time, we also show that gender affects cardiac $\beta$-MHC expression under an increased pressure load.

\section{Materials and methods}

\section{Materials}

Metoprolol tartrate salt was purchased from Sigma Chemical Co. Mouse monoclonal anti-MHC slow isoform (anti- $\beta$-MHC), mouse monoclonal anti-MHC fast isoform (anti- $\alpha$-MHC), and mouse monoclonal anti-actin were obtained from Santa Cruz Biotechnology, Inc. Anti-mouse
IgG conjugated to HRP secondary antibodies and western blot-ECL detection system were purchased from Amersham International.

\section{Animals}

All animal care and experimental procedures were in accordance with the Guide for the Care and Use of Laboratory Animals published by the US National Institutes of Health (NIH Publication No. 85-23, revised 1996) and were approved by the local ethics committee of the Italian National Institute of Health. C57BL/6 mice of both the sexes, ovariectomized C57BL/ 6 females, and orchidectomized C57BL/6 males were obtained from Harlan (S. Pietro al Natisone, Italy). $\beta$-AR KO mice (Adrb1/Adrb2 null mice, $\mathrm{D} \beta \mathrm{KO}$ ) were from a mixed $\mathrm{FVB} / \mathrm{C} 57 / 129 / \mathrm{DBA}$ genetic background, which prevents, as described previously, the high prenatal mortality induced by the $\beta 1 \mathrm{KO}$ mutation on inbred strains (Rohrer et al. 1996). As the attempts to breed these mice on a congenic background have not been successful (Bernstein et al. 2005), according to previous studies in which $\mathrm{D} \beta \mathrm{KO}$ mice were used (Bernstein et al. 2005, Ecker et al. 2006), we mated D $\beta K O$ mice with C57BL/6 mice to produce F1 mice heterozygous for both knockout genes. Thereafter, F1 heterozygous mice were mated to obtain F2 WT and D $\beta$ KO mice derived from the same mixed genetic background. Genotyping was performed on tail DNA using standard protocols.

\section{Chronic administration of metoprolol}

Metoprolol was administered in drinking water at the dose of about $100 \mathrm{mg} / \mathrm{kg}$ per day for 14 consecutive days. The dosage was chosen on the basis of literature data (Asai et al. 1999, Baumhäkel et al. 2008). In previous experiments, we found that cardiac functional changes in response to the infusion of isoprenaline, a $\beta$-AR agonist, at the dose of $30 \mathrm{ng} / \mathrm{kg}$ per min did not occur in metoprolol-treated mice (Musumeci et al. 2011). At the end of the protocol, the animals were killed, their hearts were quickly dissected, and LVs were weighed and were then frozen in liquid nitrogen and kept at $-80{ }^{\circ} \mathrm{C}$.

\section{Mouse model of LV pressure overload}

Pressure overload on the LVs was induced by thoracic aortic coarctation (TAC) for 14 days, as reported previously (Rockman et al. 1991), with some modifications. Animals were anesthetized with isoflurane $(1.5-2.0 \%$ in $100 \%$ of oxygen) and the degree of aortic stenosis was about $60 \%$.

Published by Bioscientifica Ltd. 
A control group of mice was subjected to a sham operation with an identical surgical procedure but the ligature was not tightened. To quantify the hemodynamic load imposed on the mouse LVs after aortic banding, LV systolic pressure was measured with a 1.4-Fr micromanometer-tipped catheter (Millar Instruments, mod. SPR 839, Houston, TX, USA) by direct catheterization of the LVs at the end of experiments. Data were analyzed with a software package for cardiovascular analysis (IOX 1.7; EMKA Technologies, Paris, France). In our experimental conditions, the survival rate was $100 \%$, without operation-related complications.

\section{Echocardiography}

Two weeks after banding, echocardiographic examination was performed in mice intubated and anesthetized with isoflurane ( $1 \%$ in $100 \%$ of oxygen) and set in a supine position as described previously (Patrizio et al. 2007). Left ventricular end-systolic diameter (LVESD), left ventricular end-diastolic diameter (LVEDD), and posterior wall end-diastolic thickness (PWT) were measured by an image analysis system (Metamorph; Universal Image Corporation, Dowington, PA, USA). Percent endocardial fractional shortening $(\mathrm{FS})$ was calculated as $(\mathrm{LVEDD}-\mathrm{LVESD}) / \mathrm{LVEDD} \times 100$.

\section{RNA isolation and quantification}

Total RNA was extracted from both 12-week mouse LVs and neonatal mouse hearts using SV Total RNA Isolation System (Promega). cDNA out of total RNA was synthesized using the High-Capacity cDNA Archive kit (Applied Biosystems). RNA expression levels for $\alpha$-MHC (Myh6), $\beta$-MHC (Myh7), $\beta 1$-AR (Adrb1), and $\beta 2$-AR (Adrb2) were quantified with Real-Time TaqMan RT-PCR using 7500 Real-Time PCR system (Applied Biosystems). TaqMan reactions were carried out in 96-well plates using cDNA, TaqMan universal PCR mastermix, preoptimized, and preformulated TaqMan gene expressions assays including specific primers and fluorescent probes for mouse, and water to a final volume of $50 \mu \mathrm{l}$ according to the manufacturer's instructions. The codes for each gene expressions assay were derived from the online Applied Biosystems catalogue for quantitative gene expression analysis. Glyceraldehyde 3-phosphate dehydrogenase (GAPDH) was used as an endogenous control. No reverse transcriptase and no template controls were used to monitor for any contaminating amplification. The $\Delta C \mathrm{t}$ was used for statistical analysis and $2^{-\Delta \Delta C t}$ for data presentation (Livak \& Schmittgen 2001).

\section{Western blot analysis}

Mouse LVs were lysed in Tris/ $\mathrm{HCl} 50 \mathrm{mM}$ supplemented with $1 \mathrm{mM}$ EDTA, $1 \mathrm{mM}$ EGTA, 0.5\% Triton X-100, $0.1 \%$ SDS, $1 \mathrm{mM}$ dithiothreitol, $0.2 \mathrm{mM}$ phenylmethylsulphonyl fluoride, and the protease inhibitors leupeptin $(10 \mu \mathrm{g} / \mathrm{ml})$ and aprotinin $(30 \mu \mathrm{g} / \mathrm{ml})$. Insoluble material was removed by centrifugation at $1000 \mathrm{~g}$ at $4{ }^{\circ} \mathrm{C}$ for $10 \mathrm{~min}$, and protein concentration was measured. For each condition, $25 \mu \mathrm{g}$ protein were separated by 7.5\% SDS-PAGE and transferred to nitrocellulose membranes. The membranes were then blocked with $5 \%$ nonfat milk and incubated with anti-MHC- $\alpha$, anti-MHC- $\beta$ (1:400 dilution), or with anti-actin (1:6000 dilution) for $1 \mathrm{~h}$ a $25^{\circ} \mathrm{C}$. After several washes, the membranes were incubated with secondary antibodies (anti-mouse IgG conjugated with HRP, 1:10 000) for $1 \mathrm{~h}$ at $25^{\circ} \mathrm{C}$ and visualized by the Amersham ECL system. The optical density of the bands (arbitrary units, AU) was measured with a GS-700 Imaging Densitometer (Bio-Rad), was normalized with respect to actin, and referred to the corresponding control samples (taken as 1) run in the same gel.

\section{Statistical analysis}

Group means ( \pm s.E.м.) were calculated for all relevant variables. Statistical significance between the different experimental groups was performed by ANOVA followed by Bonferroni's post hoc test in all the experiments except the western blot analysis, in which the statistical significance was evaluated by a paired Student's $t$-test. Graphpad Prism software was used. A value of $P<0.05$ was considered statistically significant.

\section{Results}

\section{Fertile female mice express greater $\beta$-MHC levels compared with age-matched males}

In the LVs of hearts from 12-week-old female mice, the levels of $\beta$-Mhc mRNA were significantly higher (about tenfold), compared with the age-matched male group, whereas no differences between the sexes were found in the expression of $\alpha-M h c$ mRNA (Fig. 1A). By contrast, no significant changes in the expression of both $\alpha$-Mhc and $\beta$-Mhc (Fig. 1A) have been detected in sexually immature animals (7 days old). The gender-based difference of $\beta$-MHC expression was confirmed by western blot analysis. Protein expression was found to be four times higher in fertile females compared with corresponding males,

Published by Bioscientifica Ltd. 


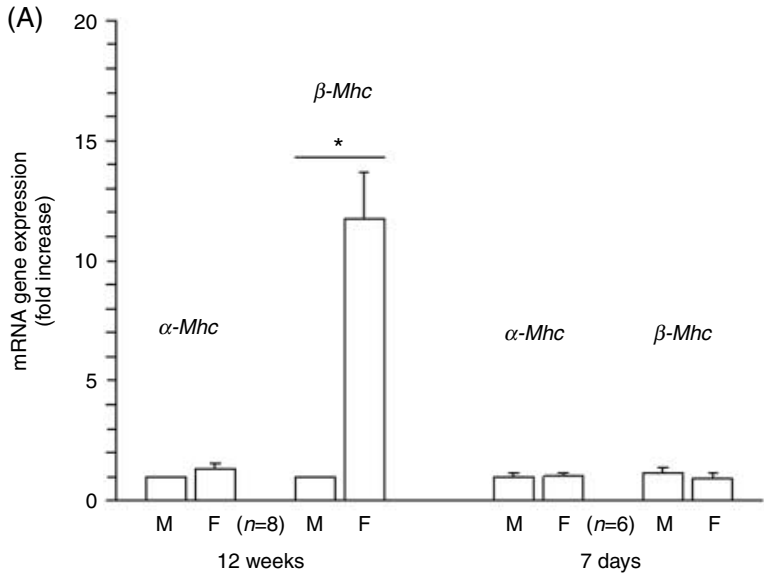

Fig. 2A, the mRNA expression of $\beta$-Mhc in orchidectomized males was the same as that of the control males. On the contrary, the expression of $\beta$-Mhc in ovariectomized females was greatly reduced compared with the control females and was even lower than that in the age-matched male group, suggesting a possible estrogen-mediated mechanism. Also in this case, the difference was specific for the $\beta$-isoform, as we did not observe significant changes in the expression of $\alpha$-Mhc (Fig. 2A).

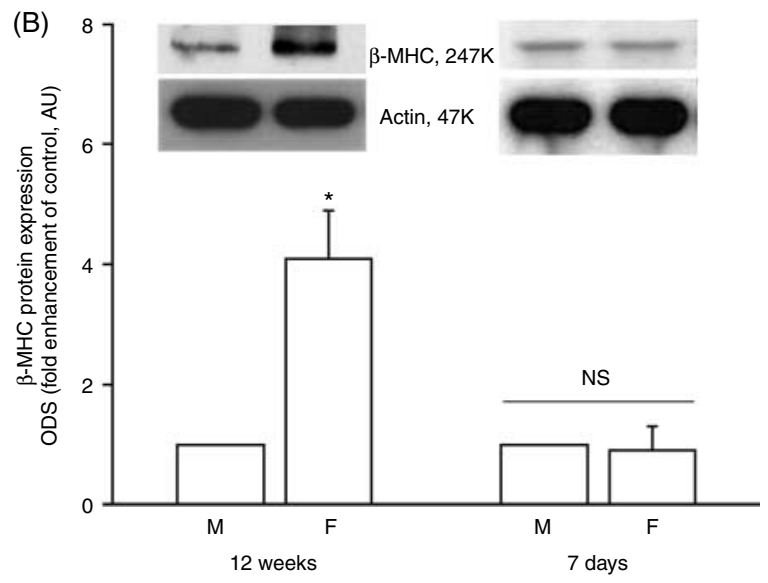

\section{$\beta 1-A R$ expression is lower in fertile female mice compared with age-matched males}

We have previously shown both in vivo and in vitro that $\beta$-AR-mediated signaling can negatively regulate fetal gene expression induced by Gq activation (Patrizio et al. 2007, 2008). Therefore, to investigate the possible involvement of $\beta$-AR in the $\beta$-MHC sex-related differences, we measured $\beta 1$ - and $\beta 2$ - $A r$ expression levels under the different experimental conditions described earlier. In adult female mice, the expression of $\beta$-Ar mRNA was $40 \%$ lower compared with agematched males, while in 7-day-old animals there was no significant difference of $\beta$-Ar expression (Fig. 2B) between the genders. Moreover, ovariectomized females expressed $\beta 1-A r$ levels similar to those of corresponding adult males (Fig. 2B). By contrast, the expression of $\beta 2$-Ar did not differ under any of the studied conditions (Fig. 2B), suggesting a specific involvement of the $\beta 1-A r$ subtype.

\section{Figure 1}

(A) $\alpha$-Mhc and $\beta$-Mhc mRNA expression in the (LVs total hearts) obtained from male (M) and female (F) mice 12-weeks-old 7 days old. Mean \pm s.E.M. of eight and six animal samples are presented respectively. ${ }^{*} P<0.05=$ significantly different from corresponding $M$ at 12 weeks using ANOVA followed by Bonferroni's post hoc test. (B) Western blot analysis of $\beta-\mathrm{MHC}$ protein levels in the LVs obtained from male (M) and female (F) mice of 12 weeks old and 7 days old. Optical density of the bands was measured with a densitometer and referred to the corresponding males (taken as 1) run in the same gel. Upper: one representative out of three performed is shown. Lower: mean \pm S.E.M. values of densitometric analysis of three distinct immunoblots. ${ }^{*} P<0.05=$ significantly different from corresponding $\mathrm{M}$ at 12 weeks using a paired Student's $t$-test. NS, not significantly different using a paired Student's $t$-test.

whereas it did not differ in prepubertal mice (Fig. 1B), suggesting a possible involvement of sex hormones in the greater expression of $\beta$-MHC observed for adult females.

\section{The gender-based difference of $\beta$-Mhc expression disappeared after ovariectomy}

In order to test this hypothesis, we studied the expression of the two myosin isoforms in the LVs of hearts obtained from 12-week-old gonadectomized mice. As shown in

\section{Genetic deletion of $\beta$-ARs abolished the sex difference in $\beta$-Mhc expression}

To further investigate the role of $\beta 1-A r$ on $\beta-M h c$ expression, we used a $\mathrm{C} 57 \mathrm{BL} / 6$-derived $\mathrm{KO}$ line of mice that carry the genetic deletion of both $\beta 1$ - and $\beta 2$-AR (D $\beta K O)$. Interestingly, in D $\mathrm{BKO}$ mice, the RNA expression of $\beta$-Mhc in the female group differed only slightly (about $45 \%$ greater) from that measured in the WT group, but it was 16-fold greater in the male group (Fig. 3A), reaching values comparable to the levels of female expression. Western blot analysis confirmed that the differences between males and females in $\beta$-Mhc expression were abolished in the absence of $\beta 1-A r$, as we did not observe significant changes in the $\alpha$-MHC and $\beta$-MHC protein levels between $\mathrm{D} \beta \mathrm{KO}$ mice of either gender (Fig. 3B).

\section{The gender-based difference of both $\beta$-Mhc and $\beta 1-A r$ expression in TAC mice}

In another set of experiments, we investigated the effect of hemodynamic overload on $\beta$-Mhc expression in the two

Published by Bioscientifica Ltd. 

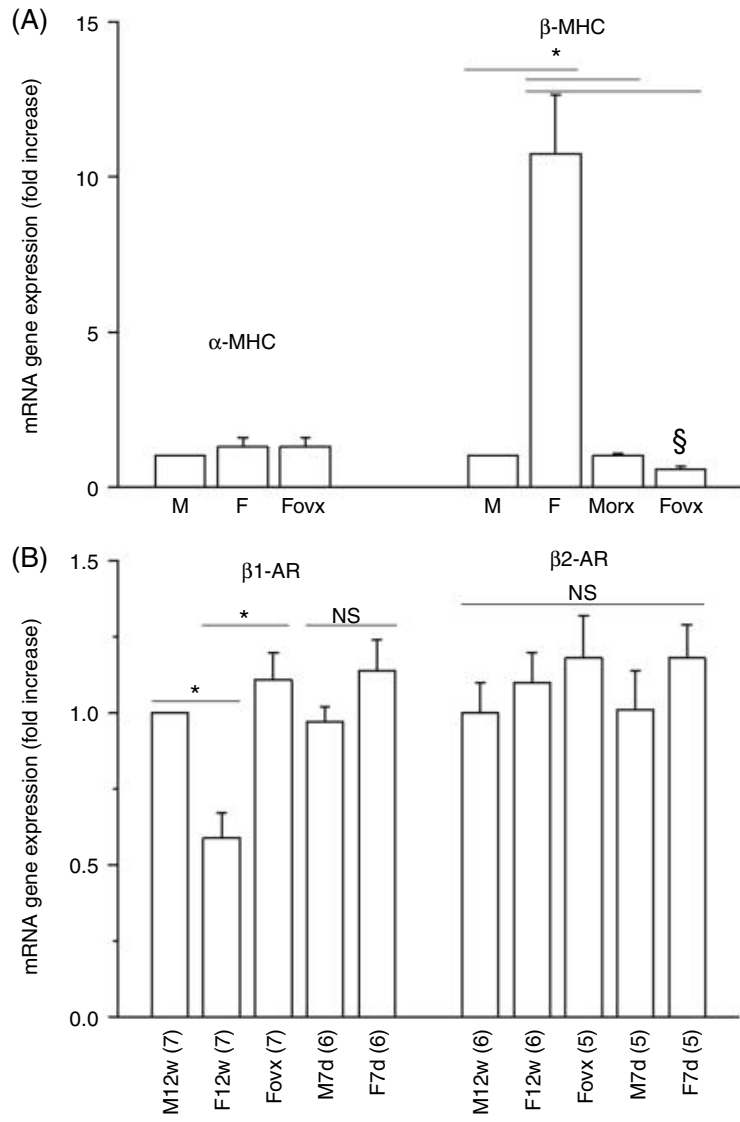

Figure 2

(A) Mhc isoforms mRNA expression in the left ventricles obtained both from ovariectomized females (Fovx, $\alpha-M h c$ and $\beta$-Mhc) and orchidectomized males (Morx, $\beta-M h c$ ) at 12 weeks of age. Mean \pm s.E.M. of seven and five animal samples are presented respectively. ${ }^{*} P<0.05=$ significantly different using ANOVA followed by Bonferroni's post hoc test. ${ }^{\S} P<0.05=$ significantly different from control male (M). (B) $\beta 1$ - and $\beta 2-A r$ expression levels in males and females at 12 weeks and 7 days of age and in ovariectomized females. Mean \pm s.E.M. of $(n)$ animal samples are presented. $* P<0.05=$ significantly different using ANOVA followed by Bonferroni's post hoc test. NS, not significantly different among the groups.

sexes. For this purpose, 12-week-old male and female mice were subjected to aortic banding (TAC) for 2 weeks. As shown in Fig. $4 \mathrm{~A}, \beta$-Mhc expression in the LVs of TAC females was similar to that expressed in sham females, whereas in males $\beta$-Mhc expression increased about 12-fold compared with their controls, reaching levels comparable to those of the female group. Moreover, TAC-treated males exhibited a $50 \%$ reduction of $\beta 1-A r$ expression levels, while in the female group the expression of this receptor was identical to that measured in the corresponding sham controls (Fig. 4B). On the contrary, the expression of $\beta 2-A r$ mRNA did not significantly differ between the male and female groups subjected to TAC (Fig. 4B).

\section{TAC-induced LVH does not differ between female and male mice}

It is also interesting to note that, despite the sharp genderrelated difference of $\beta$-Mhc expression caused by aortic banding, the increase in the left ventricular mass assessed 14 days following TAC treatment did not differ between males and females (67 and 65\% respectively), nor did we find any significant divergence in ventricular performance (assessed as endocardial FS) between the male and female groups (Table 1).

\section{Metoprolol increases $\beta-\mathrm{MHC}$ expression in male mice}

Finally, to verify whether there is a direct link between $\beta 1-A r$ signaling and the expression of $\beta-M h c$, a selective $\beta 1-A r$ antagonist metoprolol was administered to adult mice, at a dose of $100 \mathrm{mg} / \mathrm{kg}$ per day for 14 consecutive days (Asai et al. 1999, Baumhäkel et al. 2008). As shown in Fig. 5, metoprolol increased $\beta$-Mhc expression by threefold in males, whereas it failed to affect $\beta$-Mhc mRNA levels in females.

\section{Discussion}

The main finding of this study is that the greater expression of $\beta$-Mhc in the LVs of fertile female mice, compared with age-matched males, must be attributed to the presence of ovarian hormones. Two independent lines of evidence support this conclusion. First, different from what is observed between female and male adult mice, in sexually immature mice (7 days old), $\beta$-Mhc levels are similar in both sexes; secondly, in young adult ovariectomized females, the $\beta$-Mhc expression decreases, reaching the levels of corresponding adult males. On the contrary, orchidectomy does not change the $\beta$-Mhc expression, excluding an involvement of male hormones in this gender difference.

The role played by sex hormones on fetal gene expression has been poorly investigated and the few studies performed in human samples relate to elderly patients (Reiser et al. 2001, Villar et al. 2009). In animals, it has been reported that estrogen administration in ovariectomized mice subjected to TAC limited the increase in the LV mass, ANP, and $\beta$-Mhc expression (Patten et al. 2008). We believe that this discrepancy with our results, as regards the $\beta-M h c$ expression, may be the result of experimental variations, such as differences in the experimental animal model, species, and gene analysis quantification. The functional significance of different

Published by Bioscientifica Ltd. 

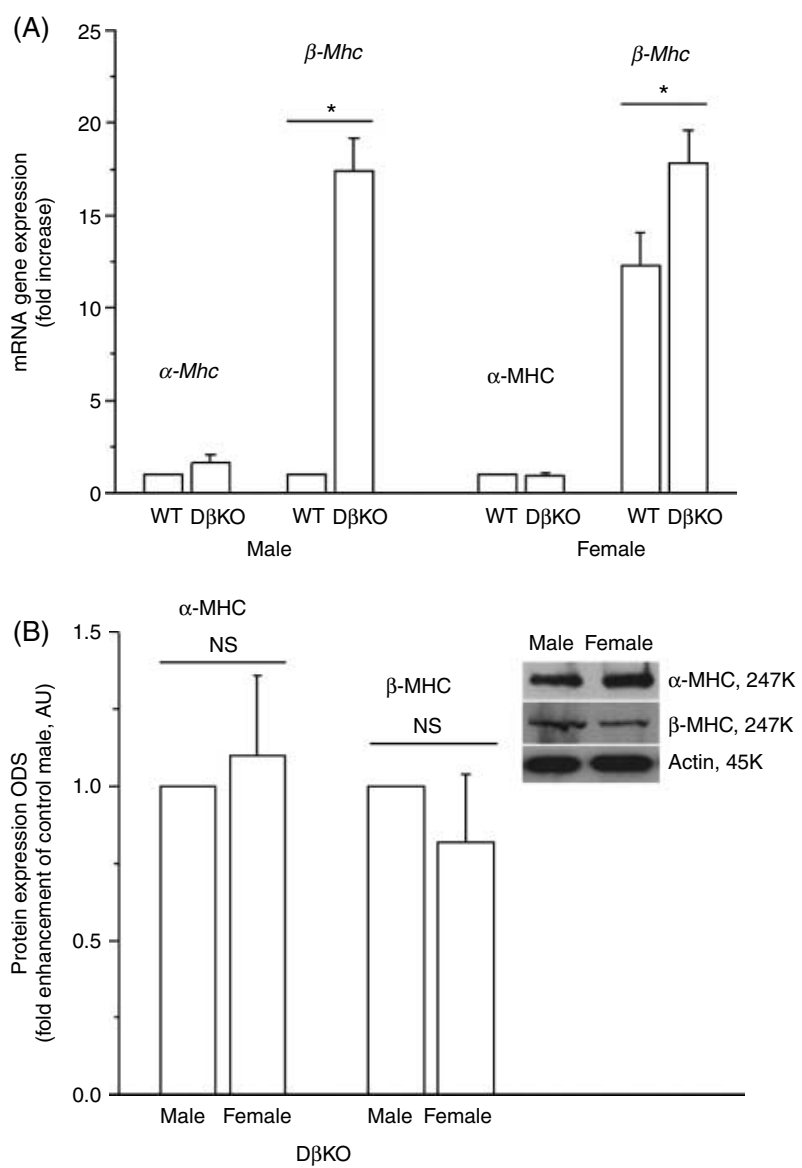

Figure 3

(A) $\alpha-M h c$ and $\beta-M h c$ mRNA expression in the LVs obtained from C57BL/6 transgenic male and female mice deprived of both $\beta 1$ - and $\beta 2$-Ars (DKO). Mean \pm S.E.M. of six and eight animal samples are presented respectively. $* P<0.05=$ significantly different using ANOVA followed by Bonferroni's post hoc test. (B) Western blot analysis of $\alpha-\mathrm{MHC}$ and $\beta-\mathrm{MHC}$ in the LVs obtained from male and female DKO mice. Optical density of the bands was measured with a densitometer and referred to the corresponding males (taken as 1) run in the same gel. Upper: one representative out of three performed is shown. Lower: mean \pm s.E.M. values of densitometric analysis of three distinct immunoblots. NS, not significantly different using a paired Student's $t$-test.

$\beta$-Mhc levels between fertile female and male mice remains to be elucidated, as well as the $\beta$-Mhc reexpression in pathological cardiac hypertrophy and other cardiac diseases. An advantageous adaptative response to pressure overload played by $\beta$-MHC reexpression was suggested some time go (Izumo et al. 1988). $\beta$-Mhc is characterized by lower ATP activity and lower filament sliding velocity but can generate a cross-bridge force with a higher economy of energy consumption than $\alpha-M h c$ (Krenz et al. 2003), thus preserving energy under hemodynamic stress conditions, such as hypertension or aortic stenosis (Lowes et al. 1997).
In agreement with an adaptive function of $\beta$-Mhc, it has recently been reported that, during pressure overloadinduced cardiac hypertrophy, cardiomyocytes with only $\alpha$-MHC develop hypertrophy after TAC, whereas the cells in which there is a new synthesis of $\beta$-MHC do not enlarge (López et al. 2011), suggesting that $\beta$-MHC expression may play an anti-hypertrophic role. Moreover, replacement of $\alpha$-MHC with $\beta$-MHC was observed to reduce hypertrophy in a troponin $\mathrm{T}$ mutant mouse (Rice et al. 2010), and an increase in myocyte total myosin and myofibrils has been reported to improve heart function (Chang et al. 1997), whereas their loss caused a worse function in human cardiomyopathy (Zimmer et al. 1992).

On the other hand, a greater expression of $\beta$-MHC has been shown to depress cardiac contractility (Tardiff
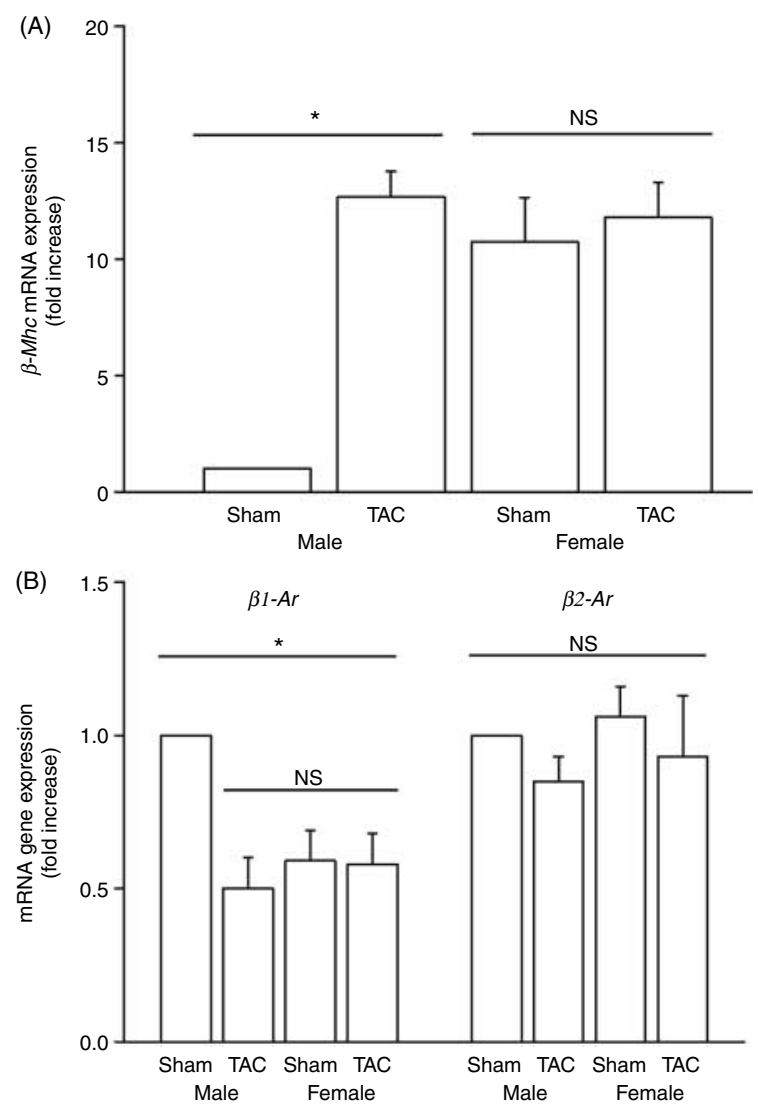

\section{Figure 4}

(A) $\beta$-Mhc mRNA expression in the LVs obtained from male and female mice subjected to TAC for 14 days. Mean \pm s.E.M. of six animal samples are presented. ${ }^{*} P<0.05=$ significantly different using ANOVA followed by Bonferroni's post hoc test. NS, not significantly different. (B) $\beta 1$ - and $\beta 2-A r$ RNA expression in TAC mice of both sexes. Mean \pm s.E.M. of six animal samples are presented. $P<0.05=$ significantly different using ANOVA followed by Bonferroni's post hoc test. NS, not significantly different among the groups. 
Table 1 Echocardiography measurements 14 days after surgery. The data represent the mean \pm S.E.M. of results obtained from ( $n$ ) animals of each condition

\begin{tabular}{|c|c|c|c|c|}
\hline & C57 male Sham & C57 male TAC & C57 female Sham & C57 female TAC \\
\hline BW (g) & $28.0 \pm 1.5(5)$ & $27.3 \pm 0.3(4)$ & $22.1 \pm 0.5(6)$ & $21.0 \pm 0.5(7)$ \\
\hline LVW (mg) & $92.0 \pm 7.0(5)$ & $150.7 \pm 0.5(4) *$ & $74.7 \pm 1.8(6)$ & $117.3 \pm 3.9(7)^{*}$ \\
\hline VW/BW & $3.3 \pm 0.1(5)$ & $3.2 \pm 0.2(4)$ & $3.2 \pm 0.2(6)$ & $3.2 \pm 0.2(7)$ \\
\hline LVEDD (mm) & $3.2 \pm 0.2(5)$ & $3.1 \pm 0.2(5)$ & $3.9 \pm 0.2(6)$ & $3.8 \pm 0.3(5)$ \\
\hline LVESD (mm) & $2.2 \pm 0.2(5)$ & $2.1 \pm 0.2(5)$ & $2.8 \pm 0.2(6)$ & $2.6 \pm 0.3(5)$ \\
\hline PWT & $0.61 \pm 0.07(5)$ & $0.91 \pm 0.04(5)$ * & $0.68 \pm 0.08(6)$ & $0.90 \pm 0.1(5) *$ \\
\hline FS (\%) & $30.9 \pm 3.8(5)$ & $32.4 \pm 2.7(5)$ & $30.6 \pm 2.2(6)$ & $31.3 \pm 3.5(5)$ \\
\hline
\end{tabular}

BW, body weight; LVW, left ventricular weight; PWT, posterior wall thickness; FS, endocardial fractional shortening. ${ }^{*} P<0.05=$ significantly different from corresponding sham group using ANOVA followed by Bonferroni's post hoc test.

et al. 2000), resulting in a poor tolerance to mechanical or pharmacological cardiovascular stress (Krenz \& Robbins 2004). In this regard, however, it has been suggested that caution must be used against genetic approaches that test the functional role of $\beta$-MHC by placing this isoform in most or all myocytes (López et al. 2011).

Our results also suggest that it is unlikely that $\beta-M h c$ expression may produce detrimental or maladaptive effects. In fact, the higher basal level of $\beta$-Mhc in females is not associated with hypertrophy or with reduced endocardial FS.

Even the data obtained by many interventions on adrenergic signaling are consistent with an adaptive function played by $\beta$-Mhc expression. The $\beta$-blocker propranolol was shown both to inhibit pressure overload-induced hypertrophy (Perlini et al. 2006, Patrizio et al. 2007) and to increase fetal gene expression (Patrizio et al. 2007, 2008), whereas a worse cardiac function was observed in an $\alpha 1$ - $A r$ KO model in which $\beta$-MHC and other fetal genes are not induced (O'Connell et al. 2006). Moreover, the $\alpha 1-A r$ blockade was reported to cause survival benefits in the evolution of hypertensive heart disease (Perlini et al. 2006). Although these observations were obtained in a more advanced phase of hypertrophy than ours, these results may be understood, at least in part, as the capability of $\alpha 1$-blockade to prevent the sympathetic overactivity-induced desensitization of $\alpha 1$-Ar, known to selectively induce $\beta$-MHC expression.

Other important findings of this study strongly suggest the involvement of $\beta 1$-Ar-mediated signaling in the regulation of $\beta$-Mhc by estrogens. We found that genetic deletion of both $\beta 1$ - and $\beta 2-A r$ abolished the gender-related difference in $\beta$-Mhc gene expression and that fertile females have reduced cardiac mRNA levels of $\beta 1$-Ar when compared with males, whereas the expression of $\beta 2-A r$ was similar in both sexes. The inhibitory effects of $\beta$-adrenergic signaling on $\beta$-Mhc expression in the hearts were previously reported. We showed that treatment with the $\beta$-blockers propranolol and metoprolol enhanced $\beta$-Mhc expression both in TAC-treated male mice and in rat-cultured cardiomyocytes stimulated with phenylephrine (Patrizio et al. 2008). In addition, here we found that metoprolol, a selective $\beta 1-\mathrm{AR}$ antagonist, is able to induce a significant increase in $\beta$-MHC expression in males. On the other hand, in studies designed to evaluate the effects of $\beta$-blockade on the fetal gene profile in failing hearts, it was reported that $\beta$-blockers decrease $\beta$-Mhc expression in patients with heart diseases (Takeo et al. 2000, Lowes et al. 2002). This discrepancy was previously discussed (Patrizio et al. 2007). A possible explanation is

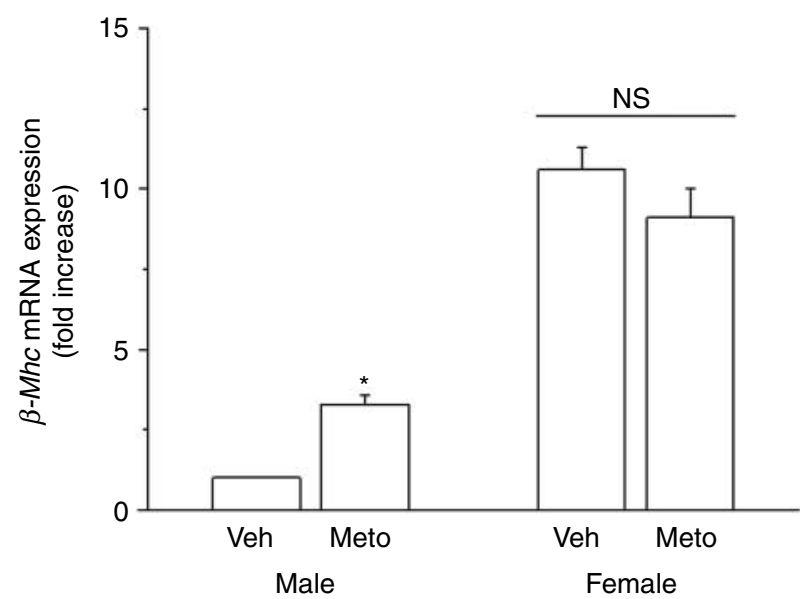

Figure 5

Effects of metoprolol (Meto) on $\beta$-Mhc mRNA expression in left ventricles obtained from male and female mice at 12 weeks of age. Mean \pm s.E.M. of six animal samples are presented. ${ }^{*} P<0.05=$ significantly different using ANOVA followed by Bonferroni's post hoc test. NS, not significantly different.

Published by Bioscientifica Ltd. 
that our results, different from others, were obtained in physiological conditions and at a very early stage of the mouse model of TAC-induced cardiac hypertrophy, when cardiac function is still unchanged. The modulation of cardiac $\beta 1-A r$ expression by ovarian hormones has already been reported in animal studies. Thawornkaiwong et al. (2003), Kam et al. (2004), and more recently Wu et al. (2008) have shown that ovariectomy upregulates $\beta 1-A r$ gene expression and protein levels in the LVs of rats, an effect that was abolished by hormone replacement therapy (HRT). The mechanism by which estrogens reduce the synthesis of $\beta 1-A R$ has not been clarified to date. It has been suggested that sex hormones, through interaction with other proteins, affect the stability of $\beta 1-A r$ mRNA in the heart (Kam et al. 2004). Further studies are needed to address this issue. In this respect, it is noteworthy that the anti-hypertrophic effect of estrogens has been shown to be linked to the inhibition of $\mathrm{Ca}^{2+} /$ calmodulin-dependent protein kinase II, known to be activated by $\beta 1$-AR through a cAMP-independent signaling pathway (Ma et al. 2009) and then limiting the inhibitory action carried out by $\beta 1-A r$ signaling on $\beta$-Mhc expression (Patrizio et al. 2008). The transition from compensated LVH to heart failure is characterized by a development of severe fibrosis, resulting in an increased deposition of collagen associated with a reduction of metalloprotease activity (Fielitz et al. 2004, Heymans et al. 2005, Tozzi et al. 2007).

It has been reported that estrogens attenuate the development of fibrosis and apoptosis induced in mice subjected to TAC (Fliegner et al. 2010). At present, the mechanism responsible for the anti-fibrotic effect of estrogens remains to be elucidated. Further research aimed at investigating whether $\beta$-MHC-positive cardiomyocytes, which in these experimental conditions were mainly observed in fibrosis areas (López et al. 2011), can play a role in counteracting extracellular matrix accumulation would be worthwhile exploring.

In conclusion, this study extends current knowledge regarding the regulation of $\beta$-MHC gene expression by demonstrating that gender and $\beta 1$-AR-mediated signaling control cardiac $\beta$-MHC levels under physiological and pathological conditions. We suggest that the greater expression of $\beta$-MHC induced by ovarian hormones in the LV of fertile female mice could have a role in the antihypertrophic effect of estrogens in the lower rate of $\mathrm{LVH}$ observed in premenopausal hypertensive women (de Simone et al. 1995, Cleland et al. 2003, Hogg et al. 2004, Regitz-Zagrosek et al. 2007) and in the cardioprotective effect played by HRT in postmenopausal hypertensive patients. Moreover, in this perspective, the involvement of $\beta 1$-AR in the regulation of cardiac $\beta$-MHC by sex hormones would in part explain the ability of the antihypertensive therapy to potentiate the anti-hypertrophic effects of HRT (Modena et al. 1999, Agabiti-Rosei and Musiesan 2002).

\section{Declaration of interest}

The authors declare that there is no conflict of interest that could be perceived as prejudicing the impartiality of the research reported.

\section{Funding}

This research did not receive any specific grant from any funding agency in the public, commercial, or not-for-profit sector.

\section{Acknowledgements}

The authors thank Dr Stefano Pieretti for his statistical analysis support and Dr Tommaso Costa for his critical reading of the manuscript and helpful suggestions.

\section{References}

Agabiti-Rosei E \& Muiesan ML 2002 Left ventricular hypertrophy and heart failure in women. Journal of Hypertension. Supplement 20 S34-S38.

Asai K, Yang GP, Geng YJ, Takagi G, Bishop S, Ishikawa Y, Shannon RP, Wagner TE, Vatner DE, Homcy CJ et al. 1999 -Adrenergic receptor blockade arrests myocyte damage and preserves cardiac function in the transgenic $\mathrm{G}(\mathrm{s} \alpha)$ mouse. Journal of Clinical Investigation 104 551-558. (doi:10.1172/JCI7418)

Baumhäkel M, Schlimmer N, Büyükafsar K, Arikan O \& Böhm M 2008 Nebivolol, but not metoprolol, improves endothelial function of the corpus cavernosum in apolipoprotein e-knockout mice. Journal of Pharmacology and Experimental Therapeutics 325 818-823. (doi:10.1124/ jpet.107.135681)

Bernstein D, Fajardo G, Zhao M, Urashima T, Powers J, Berry G \& Kobilka BK 2005 Differential cardioprotective/cardiotoxic effects mediated by $\beta$-adrenergic receptor subtypes. American Journal of Physiology. Heart and Circulation Physiology 289 H2441-H2449. (doi:10.1152/ajpheart.00005.2005)

Chang KC, Figueredo VM, Schreur JH, Kariya K, Weiner MW, Simpson PC \& Camacho SA 1997 Thyroid hormone improves function and $\mathrm{Ca}^{2+}$ handling in pressure overload hypertrophy. Association with increased sarcoplasmic reticulum $\mathrm{Ca}^{2+}$-ATPase and $\alpha$-myosin heavy chain in rat hearts. Journal of Clinical Investigation 100 1742-1749. (doi:10.1172/ JCI119699)

Cleland JG, Swedberg K, Follath F, Komajda M, Cohen-Solal A, Aguilar JC, Dietz R, Gavazzi A, Hobbs R, Korewicki J et al. 2003 The EuroHeart Failure survey programme - a survey on the quality of care among patients with heart failure in Europe. Part 1: patient characteristics and diagnosis. European Heart Journal 24 442-463. (doi:10.1016/S0195$668 \mathrm{X}(02) 00823-0)$

Douglas PS, Katz SE, Weinberg EO, Chen MH, Bishop SP \& Lorell BH 1998 Hypertrophic remodeling: gender differences in the early response to left ventricular pressure overload. Journal of the American College of Cardiology 32 1118-1125. (doi:10.1016/S0735-1097(98)00347-7)

Ecker PM, Lin CC, Powers J, Kobilka BK, Dubin AM \& Bernstein D 2006 Effect of targeted deletions of $\beta 1$ - and $\beta 2$-adrenergic-receptor subtypes on heart rate variability. American Journal of Physiology. Heart and 
Circulatory Physiology 290 H192-H199. (doi:10.1152/ajpheart. 00032.2005)

Fielitz J, Leuschner M, Zurbrügg HR, Hannack B, Pregla R, Hetzer R \& Regitz-Zagrosek V 2004 Regulation of matrix metalloproteinases and their inhibitors in the left ventricular myocardium of patients with aortic stenosis. Journal of Molecular Medicine 82 809-820. (doi:10.1007/ s00109-004-0606-4)

Fliegner D, Schubert C, Penkalla A, Witt H, Kararigas G, Dworatzek E, Staub E, Martus P, Ruiz Noppinger P, Kintscher U et al. 2010 Female sex and estrogen receptor- $\beta$ attenuate cardiac remodeling and apoptosis in pressure overload. American Journal of Physiology. Regulatory, Integrative and Comparative Physiology 298 1597-1606. (doi:10.1152/ajpregu. 00825.2009)

Heymans S, Schroen B, Vermeersch P, Milting H, Gao F, Kassner A, Gillijns H, Herijgers P, Flameng W, Carmeliet P et al. 2005 Increased cardiac expression of tissue inhibitor of metalloproteinase- 1 and tissue inhibitor of metalloproteinase- 2 is related to cardiac fibrosis and dysfunction in the chronic pressure-overloaded human heart. Circulation 112 1136-1144. (doi:10.1161/CIRCULATIONAHA.104.516963)

Hogg K, Swedberg K \& McMurray J 2004 Heart failure with preserved left ventricular systolic function; epidemiology, clinical characteristics, and prognosis. Journal of the American College of Cardiology 43 317-332. (doi:10.1016/j.jacc.2003.07.046)

Izumo S, Lompre AM, Matsuoka R, Koren G, Schwartz K, Nadal-Ginard B \& Mahdavi V 1987 Myosin heavy chain messenger RNA and protein isoform transitions during cardiac hypertrophy. Interaction between hemodynamic and thyroid hormone-induced signals. Journal of Clinical Investigation 79 970-977. (doi:10.1172/JCI112908)

Izumo S, Nadal-Ginard B \& Mahdavi V 1988 Protooncogene induction and reprogramming of cardiac gene expression produced by pressure overload. PNAS 85 339-343. (doi:10.1073/pnas.85.2.339)

Kam KW, Qi JS, Chen M \& Wong TM 2004 Estrogen reduces cardiac injury and expression of $\beta 1$-adrenoceptor upon ischemic insult in the rat heart. Journal of Pharmacology and Experimental Therapeutics 309 8-15. (doi:10.1124/jpet.103.058339)

Krenz M \& Robbins J 2004 Impact of $\beta$-myosin heavy chain expression on cardiac function during stress. Journal of the American College of Cardiology 44 2390-2397. (doi:10.1016/j.jacc.2004.09.044)

Krenz M, Sambe A, Bouyer-Dalloz F, Gulick J, Klevitsky R, Hewett TE, Osinka HE, Lorenz JN, Brosseau C, Federico A et al. 2003 Analysis of myosin heavy chain functionality in the heart. Journal of Biological Chemistry 278 17466-17474.

Livak KJ \& Schmittgen TD 2001 Analysis of relative gene expression data using real-time quantitative PCR and the 2DDCT method. Methods 25 402-408. (doi:10.1006/meth.2001.1262)

López JE, Myagmar BE, Swigart PM, Montgomery MD, Haynam S, Bigos M, Rodrigo MC \& Simpson PC $2011 \beta$-Myosin heavy chain is induced by pressure overload in a minor subpopulation of smaller mouse cardiac myocytes. Circulation Research 109 629-638. (doi:10.1161/CIRCRESAHA.111.243410)

Lowes BD, Minobe W, Abraham WT, Rizeq MN, Bohlmeyer TJ, Quaife RA, Roden RL, Dutcher DL, Robertson AD, Voelkel NF et al. 1997 Changes in gene expression in the intact human heart. Downregulation of $\alpha$-myosin heavy chain in hypertrophied, failing ventricular myocardium. Journal of Clinical Investigation 100 2315-2324. (doi:10.1172/JCI119770)

Lowes BD, Gilbert EM, Abraham WT, Minobe WA, Larrabee P, Ferguson D, Wolfel EE, Lindenfeld J, Tsvetkova T, Robertson AD et al. 2002 Myocardial gene expression in dilated cardiomyopathy treated with $\beta$-blocking agents. New England Journal of Medicine 346 1357-1365. (doi:10.1056/NEJMoa012630)

Ma Y, Cheng WT, Wu S \& Wong TM 2009 Oestrogen confers cardioprotection by suppressing $\mathrm{Ca}^{2+} /$ calmodulin-dependent protein kinase II. British Journal of Pharmacology 157 705-715. (doi:10.1111/j. 1476-5381.2009.00212.x)
Modena MG, Muia N Jr, Avet P, Molinari R \& Rossi R 1999 Effects of the transdermal $17 \beta$-estradiol on left ventricular anatomy and performance in hypertensive women. Hypertension 34 1041-1046. (doi:10.1161/01. HYP.34.5.1041)

Musumeci M, Maccari S, Sestili P, Signore M, Molinari P, Ambrosio C, Stati T, Colledge WH, Grace AA, Catalano L et al. 2011 Propranolol enhances cell cycle-related gene expression in pressure overloaded hearts. British Journal of Pharmacology 164 1917-1928. (doi:10.1111/ j.1476-5381.2011.01504.x)

O'Connell TD, Swigart PM, Rodrigo MC, Ishizaka S, Joho S, Turnbull L, Tecott LH, Baker AJ, Foster E, Grossman W et al. $2006 \propto 1$-Adrenergic receptors prevent a maladaptive cardiac response to pressure overload. Journal of Clinical Investigation 116 1005-1015. (doi:10.1172/JCI22811)

Patrizio M, Musumeci M, Stati T, Fasanaro P, Palazzesi S, Catalano L \& Marano G 2007 Propranolol causes a paradoxical enhancement of cardiomyocyte fetal gene response to hypertrophic stimuli. British Journal of Pharmacology 152 216-222. (doi:10.1038/sj.bjp.0707350)

Patrizio M, Vago V, Musumeci M, Fecchi K, Sposi NM, Mattei E, Catalano L, Stati T \& Marano G 2008 cAMP-mediated $\beta$-adrenergic signaling negatively regulates Gq-coupled receptor-mediated fetal gene response in cardiomyocytes. Journal of Molecular and Cellular Cardiology $\mathbf{4 5}$ 761-769. (doi:10.1016/j.yjmcc.2008.09.120)

Patten RD, Pourati I, Aronovitz MJ, Alsheikh-Ali A, Eder S, Force T, Mendelsohn ME \& Karas RH 2008 17 $\beta$-Estradiol differentially affects left ventricular and cardiomyocyte hypertrophy following myocardial infarction and pressure overload. Journal of Cardiac Failure 14 245-253. (doi:10.1016/j.cardfail.2007.10.024)

Perlini S, Ferrero I, Palladini G, Tozzi R, Gatti C, Vezzoli M, Cesana F, Janetti MB, Clari F, Busca G et al. 2006 Survival benefits of different antiadrenergic interventions in pressure overload left ventricular hypertrophy/failure. Hypertension 48 93-97. (doi:10.1161/01.HYP. 0000226859.42064.ea)

Pfeffer JM, Pfeffer MA, Fletcher P, Fishbein MC \& Braunwald E 1982 Favorable effects of therapy on cardiac performance in spontaneously hypertensive rats. American Journal of Physiology 242 776-784.

Regitz-Zagrosek V, Brokat S \& Tschope C 2007 Role of gender in heart failure with normal left ventricular ejection fraction. Progress in Cardiovascular Diseases 49 241-251. (doi:10.1016/j.pcad.2006.08.011)

Reiser PJ, Portman MA, Ning XH \& Schomish Moravec C 2001 Human cardiac myosin heavy chain isoforms in fetal and failing adult atria and ventricles. American Journal of Physiology. Heart and Circulatory Physiology $280 \mathrm{H} 1814-\mathrm{H} 1820$.

Rice R, Guinto P, Dowell-Martino C, He H, Hoyer K, Krenz M, Robbins J, Ingwall JS \& Tardiff JC 2010 Cardiac myosin heavy chain isoform exchange alters the phenotype of cTnT-related cardiomyopathies in mouse hearts. Journal of Molecular and Cellular Cardiology 48 979-988. (doi:10.1016/j.yjmcc.2009.11.018)

Rockman HA, Ross RS, Harris AN, Knowlton KU, Steinhelper ME, Field LJ, Ross J Jr \& Chien KR 1991 Segregation of atrial-specific and inducible expression of an atrial natriuretic factor transgene in an in vivo murine model of cardiac hypertrophy. PNAS $\mathbf{8 8} 8277-8281$. (doi:10.1073/pnas. 88.18.8277)

Rohrer DK, Desai KH, Jasper JR, Stevens ME, Regula DP Jr, Barsh GS, Bernstein D \& Kobilka BK 1996 Targeted disruption of the mouse $\beta 1$-adrenergic receptor gene: developmental and cardiovascular effects. PNAS 93 7375-7380. (doi:10.1073/pnas.93.14.7375)

de Simone G, Devereux RB, Daniels SR \& Meyer RA 1995 Gender differences in left ventricular growth. Hypertension 26 979-983. (doi:10.1161/01. HYP.26.6.979)

Skavdahl M, Steenbergen C, Clark J, Myers P, Demianenko T, Mao L, Rockman HA, Korach KS \& Murphy E 2005 Estrogen receptor- $\beta$ mediates male-female differences in the development of pressure overload hypertrophy. American Journal of Physiology. Heart and Circulatory Physiology 288 H469-H476. (doi:10.1152/ajpheart. 00723.2004) 
Takeo S, Elmoselhi AB, Goel R, Sentex E, Wang J \& Dhalla NS 2000 Attenuation of changes in sarcoplasmic reticular gene expression in cardiac hypertrophy by propranolol and verapamil. Molecular and Cellular Biochemistry 213 111-118. (doi:10.1023/A:1007120332587)

Tardiff JC, Hewett TE, Factor SM, Vikstrom KL, Robbins J \& Leinwand LA 2000 Expression of the $\beta$ (slow)-isoform of MHC in the adult mouse heart causes dominant-negative functional effects. American Journal of Physiology. Heart and Circulatory Physiology 278 H412-H419.

Thawornkaiwong A, Preawnim S \& Wattanapermpool J 2003 Upregulation of $\beta 1$-adrenergic receptors in ovariectomized rat hearts. Life Sciences $\mathbf{7 2}$ 1813-1824. (doi:10.1016/S0024-3205(02)02473-6)

Tozzi R, Palladini G, Fallarini S, Nano R, Gatti C, Presotto C, Schiavone A, Micheletti R, Ferrari P, Fogari R et al. 2007 Matrix metalloprotease activity is enhanced in the compensated but not in the decompensated phase of pressure overload hypertrophy. American Journal of Hypertension 20 663-669. (doi:10.1016/j.amjhyper.2007.01.016)

Villar AV, Llano M, Cobo M, Expósito V, Merino R, Martín-Durán R, Hurlé MA \& Nistal JF 2009 Gender differences of echocardiographic and gene expression patterns in human pressure overload left ventricular hypertrophy. Journal of Molecular and Cellular Cardiology $\mathbf{4 6}$ 526-535. (doi:10.1016/j.yjmcc.2008.12.024)

Weinberg EO, Thienelt CD, Katz SE, Bartunek J, Tajima M, Rohrbach S, Douglas PS \& Lorell BH 1999 Gender differences in molecular remodeling in pressure overload hypertrophy. Journal of the American College of Cardiology 34 264-273. (doi:10.1016/S0735-1097(99)00165-5)

Wu Q, Zhao Z, Sun H, Hao YL, Yan CD \& Gu SL 2008 Oestrogen changed cardiomyocyte contraction and $\beta$-adrenoceptor expression in rat hearts subjected to ischaemia-reperfusion. Experimental Physiology 93 1034-1043. (doi:10.1113/expphysiol.2007.041939)

Zimmer G, Zimmermann R, Hess OM, Schneider J, Kübler W, Krayenbuehl HP, Hagl S \& Mall G 1992 Decreased concentration of myofibrils and myofiber hypertrophy are structural determinants of impaired left ventricular function in patients with chronic heart diseases: a multiple logistic regression analysis. Journal of the American College of Cardiology 20 1135-1142. (doi:10.1016/0735-1097 (92)90369-X)

Received in final form 18 November 2012

Accepted 22 November 2012

Accepted Preprint published online 22 November 2012
() 2013 Society for Endocrinology Printed in Great Britain
Published by Bioscientifica Ltd. 